\title{
Effects of front and back squat techniques on patellofemoral joint kinetics in males
}

\author{
Sinclair $\mathrm{J}^{1}$, Atkins $\mathrm{S}^{1}$, Kudiersky $\mathrm{N}^{1}$, Taylor $\mathrm{PJ}^{2}$, Vincent $\mathrm{H}^{1}$ \\ 1. Division of Sport Exercise and Nutritional Sciences, School of Sport Tourism and Outdoors, University of Central \\ Lancashire, United Kingdom. 2. School of Psychology, University of Central Lancashire, United Kingdom.
}

Correspondence: Jonathan Sinclair. Address: Division of Sport, Exercise and Nutritional Sciences, School of Sport Tourism and Outdoors, University of Central Lancashire, Preston, Lancashire, PR1 2HE, United Kingdom.

Email: Jksinclair@uclan.ac.uk

Received: August 16, 2015

DOI : $10.5430 /$ jbei.v2n1p76

Accepted: September 20, 2015

Online Published: October 14, 2015

URL: http://dx.doi.org/10.5430/jbei.v2n1p76

\section{Abstract}

Purpose: The barbell squat is fundamental in strength and conditioning, with two principal variants; the back and front squat. Unfortunately, the propensity for injury is high particularly at the knee. The aim of the current investigation was examine the influence of front and back squat variations on patellofemoral joint load.

Methods: Patellofemoral loads were obtained from thirty-five experienced male participants, who completed both back and front squats at $70 \%$ of $1 \mathrm{RM}$. Differences between squat conditions were examined using Bonferroni adjusted $(P=.008)$ paired $t$-tests.

Results: The results showed that significant differences $(P<.008)$ in patellofemoral load were identified between both conditions with the highest load being experienced during the back squat exercise.

Conclusions: Given the proposed relationship between the magnitude of the load experienced by the patellofemoral joint and associated injury pathology, the back squat appears to place lifters at greater risk from injury. Therefore, it may be prudent therefore for lifters who are predisposed to patellofemoral pain syndrome to utilize the front squat in their training.

\section{Key words}

Biomechanics, Squat, Patellofemoral pain

\section{Introduction}

The squat is a central lift in the field of strength and conditioning ${ }^{[1]}$, which serves to actively recruits the quadriceps, hamstrings, gluteus and gastrocnemius muscles ${ }^{[1,2]}$, and as a multi-joint closed chain kinetic movement is considered one of the most functional weight training exercises ${ }^{[3]}$. The two principal variants of the squat are the back and the front squat lifts. Although both squats are mechanically similar, slight variations exist in terms of technique and muscular involvement ${ }^{[4-6]}$. 
Unfortunately, due to the nature of the barbell squat, high levels of flexion at the knee joint means that the propensity for injury is high, particularly at the knee itself ${ }^{[7-10]}$. Patellofemoral pain syndrome is the most frequently encountered chronic pathology of the knee in athletic populations ${ }^{[11,12]}$. Patellofemoral pain is linked to chronic overloading of the patellofemoral joint itself, during dynamic activities ${ }^{[13,14]}$. Such disorders can be debilitating, and patellofemoral pain syndrome has been identified as a pre-cursor to the advancement of osteoarthritis in later life ${ }^{[15]}$. It is therefore important to better understand the forces that are produced through the patellofemoral joint when different squat techniques are employed. Although previous analyses have considered the biomechanical variations between the front and back squat lifts, there remains little clinical research concerning the two squat modalities regarding the stresses experienced by the patellofemoral joint itself.

The aim of the current investigation was to examine the effects of the front and back squat techniques on the loads experienced by the patellofemoral joint. A study of this nature may provide important clinical information to those who habitually engage in squatting activities, regarding their susceptibility to patellofemoral pain symptoms when performing different variants of the lift. The current investigation tests the hypothesis that patellofemoral forces will be greater when performing the back squat.

\section{Methods}

\subsection{Participants}

Thirty-five male participants (age $25.66 \pm 4.58$ years, height $1.74 \pm 0.12 \mathrm{~m}$, body mass $74.37 \pm 5.58 \mathrm{~kg}$ ), who were experienced in both front and back squat lifting, took part in the this work. Participants were experienced recreational lifters, who trained using the squat at least 3 times each week. Ethical approval was obtained from the University of Central Lancashire STEM Ethical panel.

\subsection{Procedure}

Participants each completed five repetitions in each squat condition, using their normal squat technique. The load was consistent for both conditions, with participants lifting 70\% of their back squat 1 repetition maximum. Participants completed their squats in a randomised order. To acquire knee joint kinetic information, the right foot was positioned onto a piezoelectric force platform (Kistler Instruments Ltd., Alton, Hampshire) which operated at a sampling frequency of $1,000 \mathrm{~Hz}$.

Figure 1. Marker configuration used in the current investigation

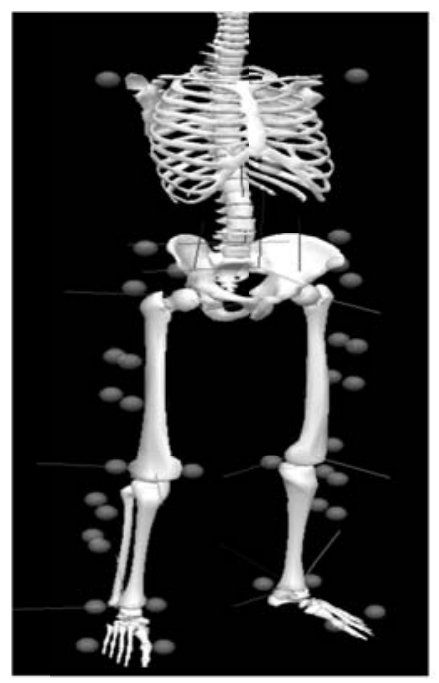


Movement data was collected at a capture $250 \mathrm{~Hz}$ using an optoelectric motion analysis system (QualisysTM Medical AB, Goteburg, Sweden). To obtain knee joint kinetics and kinematics the calibrated anatomical systems technique (CAST) was used $^{[16]}$. To define the anatomical frames of the right shank and thigh, retroreflective markers were placed onto the medial and lateral malleoli, medial and lateral femoral epicondyles and greater trochanter landmarks. In addition carbon-fibre tracking clusters comprising of four non-linear markers were placed onto the thigh and shank segments. Static calibration trials were recorded with the participant in the anatomical position allowing the positions of the anatomical markers to be referenced in relation to the tracking clusters/markers (see Figure 1).

\subsection{Data processing}

Knee joint kinetics and kinematics were analysed using Visual 3D (C-Motion, Germantown, MD, USA). Ground reaction force and 3D marker trajectories were filtered using a low pass Butterworth 4th order zero-lag filter at cut-off frequencies of 50 and $6 \mathrm{~Hz}$ respectively. 3D kinematics of the knee were calculated using an XYZ cardan sequence of rotations. Kinematic curves were normalized to $100 \%$ of the squat movement. Knee joint moments were calculated using Newton-Euler inverse-dynamics. The net joint moments were normalized to body mass and $(\mathrm{Nm} / \mathrm{kg})$.

A previously utilized musculoskeletal model was used to determine patellofemoral contact force and pressure ${ }^{[17]}$. This algorithm has been used in previous work to successfully resolve differences in patellofemoral contact force (PTCF) and pressure $(P C P)$ when wearing different footwear ${ }^{[14,18,19]}$ and between those with and without patellofemoral pain ${ }^{[20]}$. PTCF (B.W) during the squat was quantified as a product of knee flexion angle ( $f a$ ) and knee extensor moment $(M E)$ according to the model described by Ho et al. ${ }^{[14]}$. The moment arm of the quadriceps muscle $(m q)$ was quantified as a function of knee flexion angle using non-linear equation (1), based on cadaveric information presented by van Eijden et al. ${ }^{[21]}$.

$$
m q=0.00008 f a^{3}-0.013 f a^{2}+0.28 f a+0.046
$$

Quadriceps force $(Q F)(2)$ was then calculated using the below formula:

$$
Q F=M E / m q
$$

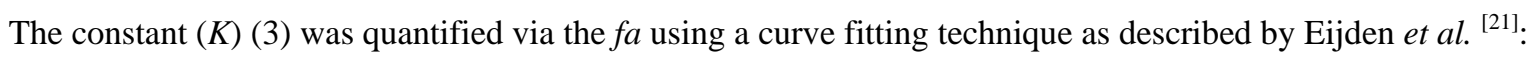

$$
\mathrm{K}=\left(0.462+0.00147 f a^{2}-0.0000384 f a^{2}\right) /\left(1-0.0162 f a+0.000155 f a^{2}-0.000000698 f a^{3}\right)
$$

PTCF (4) was estimated using the $Q F$ and a constant:

$$
P T C F=Q F \times K
$$

PCP (MPa) (5) was calculated as a function of the PTCF divided by the patellofemoral contact area. The patellofemoral contact area was described in accordance with the Salsich et al., ${ }^{[22]}$ recommendations.

$$
P C P=P T C F / \text { contact area }
$$

\subsection{Statistical analyses}

Differences in between the two squat conditions were examined using paired samples $t$-tests. The criterion for statistical significance was altered to $P=.008$ using a Bonferroni adjustment to reduce the type I error rate. Effect sizes were calculated using a Cohen’s D. All statistical tests were undertaken using SPSS 21.0 (SPSS Inc., Chicago, USA). 


\section{Results}

Table 1 and Figure 2 show the knee kinetics and kinematics from each squat technique. The results show that whilst the kinetics/kinematic curves from the two conditions were qualitatively similar, squat technique significantly influenced patellofemoral kinetics.

Figure 2. Knee/kinetics and kinematics as a function of the different squat techniques (Black = back squat \& Dash = front squat) $(\mathrm{a}=$ sagittal knee angle, $\mathrm{b}=$ sagittal knee moment, $\mathrm{c}=$ patellofemoral force, $\mathrm{d}=$ patellofemoral pressure, e = coronal knee moment)

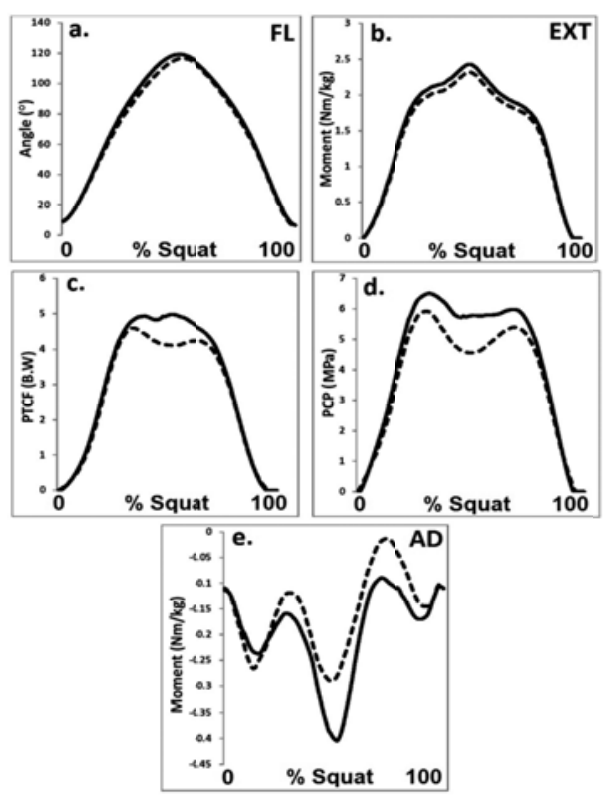

Table 1. Patellofemoral joint force parameters (mean standard \pm deviation) as a function of the different squat techniques

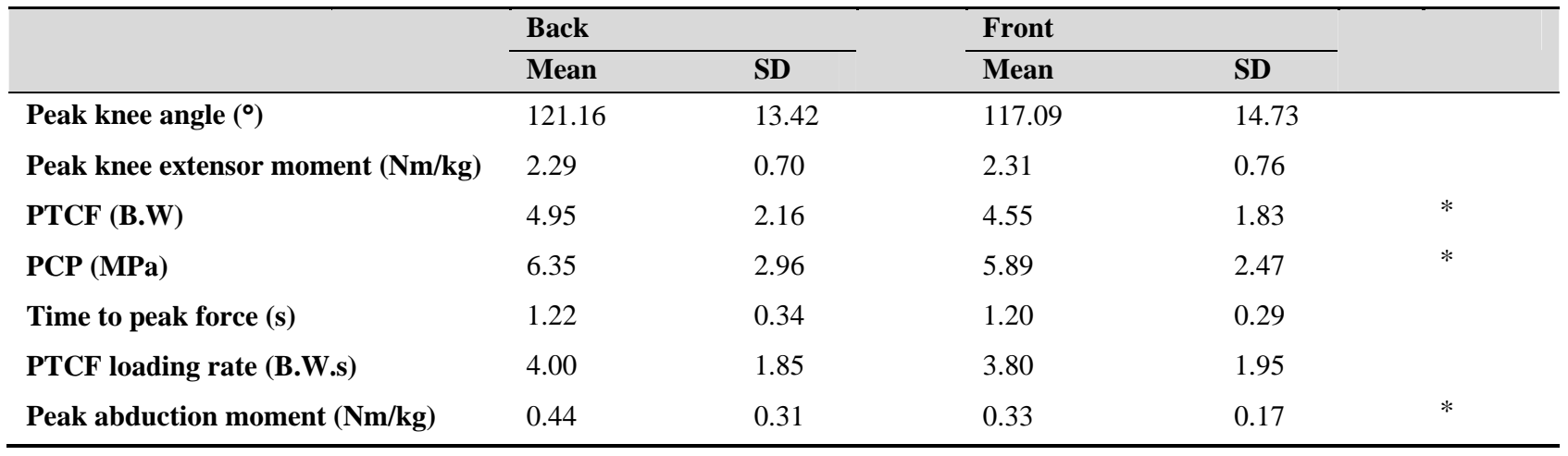

Note. $*=$ significant difference.

The results show that peak PTCF was significantly larger $(t(34)=3.43, P<.008, \mathrm{D}=1.18)$ in the back squat compared to the front squat condition (see Table 1; Figure 2c). Peak PCP was also shown to be significantly larger $(t$ (34) $=4.11$, $P<.008, \mathrm{D}=1.41$ ) in the back squat compared to the front squat condition (see Table 1; Figure 2d). Finally peak abduction moment was shown to be significantly $(t(34)=2.55, P<.008, \mathrm{D}=0.87$ ) larger in the back squat compared to the front (see Table 1; Figure 2e).

\section{Discussion}

The aim of the current study was to examine effects of the front and back squat techniques on the loads experienced by the patellofemoral joint. This study represents the first to examine the influence of the front and back squat techniques on the forces experienced by the patellofemoral joint and may provide insight into the most appropriate method to use for those susceptible to knee pathology. 
Importantly the current work showed that the back squat was associated with a significantly increased PTCF and PCP compared to the front squat. This observation concurs with the findings of Gullett et al., ${ }^{[6]}$ who showed that knee loads were significantly larger in the back squat. This observation may have clinical relevance and provide insight into the mechanisms by which different squat techniques may serve to reduce the prevalence of patellofemoral pain. The aetiology and progression of patellofemoral pain symptoms are considered to be a function of habitual and excessive loads experienced by the patellofemoral joint itself ${ }^{[13,14]}$. This study therefore indicated that those who habitually utilize the back squat in favour of the front squat may be at increased risk from patellofemoral degradation. Our findings further highlight that weight lifters who are susceptible to patellofemoral disorders may wish to adopt the front squat as a mechanism of reducing their risk of knee pathology.

An additional clinically important consideration from this study is that the back squat was associated with a significantly increased peak knee abduction moment compared to the front squat. Increased peak knee abduction moments have been linked with greater medial compartment loading ${ }^{[23]}$ and have also been linked to the initiation of other chronic knee pathologies such as tibiofemoral osteoarthritis ${ }^{[24]}$. It has also been further proposed that an enhanced knee abduction moment serves to augment loading at the lateral facet of the patellofemoral joint articulation and thus may also contribute to the development of patellofemoral pain symptoms ${ }^{[25]}$.

A potential limitation of this work is that patellofemoral kinetics were resolved using a musculoskeletal model. This was unavoidable due to the invasive nature of generating in vivo measurements of patellofemoral forces. Whilst the model used in the current study has been used previously to observed differences in patellofemoral kinetics during squatting ${ }^{[26]}$, this technique may nonetheless have underestimated PTCF and PCP as the knee extensor moment cannot not take into account the antagonist force generation that acts in the opposing direction of the joint. Muscle driven simulations of joint loading using inverse kinematics have received considerable interest in recent years ${ }^{[27]}$, and with further work to improve their accuracy further advancements in musculoskeletal research are possible. A further potential limitation to the current work is that only male weightlifters were examined. Females are at much greater risk from patellofemoral pain symptoms ${ }^{[28]}$ and are also known to exhibit distinct knee joint kinetics and kinematics in comparison to males ${ }^{[29]}$. Therefore the findings from the current investigation may not be applicable to female weight lifters. It is recommended therefore that the current investigation be repeated using a female sample.

In conclusion, although previous analyses have comparatively examined the mechanics of front and back squat the current knowledge with regards to the differences in patellofemoral loads between the two modalities is limited. The current investigation addresses this by providing a comparison of patellofemoral forces between the front and back squat lifts. The current study shows that the front squat condition was associated with significant reductions in patellofemoral kinetic parameters compared to the back squat. Given the proposed relationship between the magnitude of the load experienced by the patellofemoral joint during dynamic activities and knee pathology, it is suggested that the risk from developing related injuries to the patellofemoral joint may be attenuated through more frequent utilization of the front squat.

\section{References}

[1] Escamilla RF, Fleisig GS, Lowry TM, et al. A three-dimensional biomechanical analysis of the squat during varying stance widths. Med Sci Sport Ex. 2001; 33: 984-98. http://dx.doi.org/10.1097/00005768-200106000-00019

[2] Escamilla RF, Fleisig GS, Zheng $\mathrm{N}$, et al. The effects of technique variations on knee biomechanics duringn the squat and leg press. Med Sci Sport Ex. 2001; 33(9): 1552-66. http://dx.doi.org/10.1097/00005768-200109000-00020

[3] McCaw ST, Melrose DR. Stance width and bar load effects on leg muscle activity during the parallel squat. Med Sci Sport Ex. 1999; 31: 428-36. http://dx.doi.org/10.1097/00005768-199903000-00012

[4] Russell PJ, Phillips SJ. A preliminary comparison of front and back squat exercises. Res Q Exerc Sport. 1989; 60: 201-8. PMid:2489844. http://dx.doi.org/10.1080/02701367.1989.10607441

[5] Braidot AA, Brusa MH, Lestussi FE, et al. Biomechanics of front and back squat exercises. J Physics: Conference Series. 2007 IOP Publishing; 90. 
[6] Gullett JC, Tillman MD, Gutierrez GM, et al. A biomechanical comparison of back and front squats in healthy trained individuals. J Strength Cond Res. 2009; 23: 284-92. PMid:19002072. http://dx.doi.org/10.1519/JSC.0b013e31818546bb

[7] Griffin LY. Rehabilitation of the extensor mechanism. In: Fox JM, Del Pizzo W, eds. The Patellofemoral Joint. New York, McGraw-Hill Inc. 1993; 279-90.

[8] Dahlkvist NJ, Mayo P, Seedhom BB. Forces during squatting and rising from a deep squat. Eng Med. 1982; 11 : 69-76. PMid:7201419. http://dx.doi.org/10.1243/EMED_JOUR_1982_011_019_02

[9] Reilly DT, Martens M. Experimental analysis of the quadriceps muscle force and patellofemoral joint reaction force for various activities. Acta Orthop Scand. 1972; 43: 126-37. http://dx.doi.org/10.3109/17453677208991251

[10] Wilson NA, Press JM, Koh JL, et al. In vivo noninvasive evaluation of abnormal patellar tracking during squatting in patients with patellofemoral pain. J Bone Joint Surg. 2009; 91: 558-66. PMid:19255215. http://dx.doi.org/10.2106/JBJS.G.00572

[11] LaBella C. Patellofemoral pain syndrome: evaluation and treatment. Prim Care. 2004; 31: 977-1003. PMid:15544830. http://dx.doi.org/10.1016/j.pop.2004.07.006

[12] Dugan SA. Sports related knee injuries in female athletes: what gives? Am J Phys Med Rehabil. 2005; 84: 122-30. PMid:15668560. http://dx.doi.org/10.1097/01.PHM.0000154183.40640.93

[13] Fulkerson JP, Arendt EA. Anterior knee pain in females. Clin Orthop Relat Res. 2000; 372: 69-73. http://dx.doi.org/10.1097/00003086-200003000-00009

[14] Ho KY, Blanchette MG, Powers CM. The influence of heel height on patellofemoral joint kinetics during walking. Gait Posture. 2012; 36: 271-5. PMid:22520457. http://dx.doi.org/10.1016/j.gaitpost.2012.03.008

[15] Thomas MJ, Wood L, Selfe J, et al. Anterior knee pain in younger adults as a precursor to subsequent patellofemoral osteoarthritis: a systematic review. BMC Musculoskelet Disord. 2010; 11: 201. PMid:20828401. http://dx.doi.org/10.1186/1471-2474-11-201

[16] Cappozzo A, Catani F, Leardini A, et al. Position and orientation in space of bones during movement: anatomical frame definition and determination. Clin Biomech. 1995; 10: 171-8. http://dx.doi.org/10.1016/0268-0033(95)91394-T

[17] Ward SR, Powers CM. The influence of patella alta on patellofemoral joint stress during normal and fast walking. Clin Biomech. 2004; 19: 1040-7. PMid:15531054. http://dx.doi.org/10.1016/j.clinbiomech.2004.07.009

[18] Bonacci J, Vicenzino B, Spratford W, et al. Take your shoes off to reduce patellofemoral joint stress during running. Br J Sp Med. 2013.

[19] Kulmala JP, Avela J, Pasanen K, et al. Forefoot strikers exhibit lower running-induced knee loading than rearfoot strikers. Medicine \& Science in Sports \& Exercise. 2013; 45: 2306-13. PMid:23748735. http://dx.doi.org/10.1249/MSS.0b013e31829efcf7

[20] Keino BJ, Powers CM. Patellofemoral stress during walking in persons with and without patellofemoral pain. Med Sci Sport Ex. 2002; 34: 1582-93. http://dx.doi.org/10.1097/00005768-200210000-00009

[21] Van Eijden TM, Kouwenhoven E, Verburg J, et al. A mathematical model of the patellofemoral joint. J Biomech. 1986; 19: 21929. http://dx.doi.org/10.1016/0021-9290(86)90154-5

[22] Salsich GB, Perman WH. Patellofemoral joint contact area is influenced by tibiofemoral rotation alignment in individuals who have patellofemoral pain. J Orthop Sports Phys Ther. 2007; 37: 521-8. PMid:17939611. http://dx.doi.org/10.2519/jospt.2007.37.9.521

[23] Zhao D, Banks SA, Mitchell KH, et al. Correlation between the knee adduction torque and medial contact force for a variety of gait patterns. J Orthop Res. 2007; 25: 789-97. PMid:17343285. http://dx.doi.org/10.1002/jor.20379

[24] Miyazaki T, Wada M, Kawahara H, et al. Dynamic load at baseline can predict radiographic disease progression in medial compartment knee osteoarthritis. Ann. Rheum Dis. 2002; 61: 617-22. http://dx.doi.org/10.1136/ard.61.7.617

[25] Sigward SM, Pollard CD, Powers CM. The influence of sex and maturation on landing biomechanics: implications for anterior cruciate ligament injury. Scand J Med Sci in Sport. 2012; 22: 502-9. PMid:21210853. http://dx.doi.org/10.1111/j.1600-0838.2010.01254.x

[26] Sinclair J, Bentley I, Kudiersky N, et al. Effects of four different relative loads on knee joint kinetics during the barbell back squat. JMEST. 2015; 2: 286-90.

[27] Delp SL, Anderson FC, Arnold AS, et al. OpenSim: open-source software to create and analyze dynamic simulations of movement. IEEE Trans Biomed Eng. 2007; 54: 1940-50. PMid:18018689. http://dx.doi.org/10.1109/TBME.2007.901024

[28] Boling M, Padua D, Marshall S, et al. Gender differences in the incidence and prevalence of patellofemoral pain syndrome. Scand J Med Sci Sport. 2010; 20: 725-30. PMid:19765240. http://dx.doi.org/10.1111/j.1600-0838.2009.00996.x

[29] Sinclair J, Selfe J. Sex differences in knee loading in recreational runners. J Biomech. 2015; 48: 2171-5. PMid:26054425. http://dx.doi.org/10.1016/j.jbiomech.2015.05.016 